\title{
The Challenge of HFpEF Diagnosis in Brazil
}

\author{
Luiz Cláudio Danzmann, ${ }^{1,2}$ Evgeny Belyavskiy, ${ }^{3,4}$ Antônio José Lagoeiro Jorge, ${ }^{5}$ Evandro Tinoco Mesquita, ${ }^{5}$ (๑ \\ Marco Antonio Rodrigues Torres ${ }^{6}$ \\ Universidade Luterana do Brasil (ULBRA), ${ }^{1}$ Canoas, RS - Brazil \\ Hospital São Lucas da PUC-RS, ${ }^{2}$ Porto Alegre, RS - Brazil \\ Department of Internal Medicine and Cardiology, Campus Virchow-Klinikum Charité, ${ }^{3}$ Universitätsmedizin Berlin - Germany \\ German Center for Cardiovascular Research (DZHK), ${ }^{4}$ partner site Berlin - Germany \\ Universidade Federal Fluminense (UFF), ${ }^{5}$ Niterói, RJ - Brazil \\ Programa de Pós-Graduação em Ciências Pneumológicas da Universidade Federal do Rio Grande do Sul (UFRGS), ${ }^{6}$ Porto Alegre, RS - Brazil
}

\section{Abstract}

Heart failure with preserved ejection fraction (HFpEF) is highly prevalent in Brazil and worldwide. However, the recent diagnostic criteria for this condition are complex and difficult to apply in the Brazilian health system. This review proposes adapting the modern diagnostic criteria to the needs of each patient, from the primary care to the most complex one, using a system of three steps of complexity and highlighting the importance of searching specific disease etiology.

Heart failure with preserved ejection fraction (HFpEF) remains a major public health problem worldwide and also in Brazil. ${ }^{1}$ The recognition and diagnosis of this syndrome remain a challenge, due to its physiopathological complexity and phenotypic diversity.

The current scientific evidence on etiopathogenesis provided more accurate diagnostic recommendations but requires comprehensive echocardiographic analysis..$^{2,3}$ A recently published recommendation from the Heart Failure Association of the European Society of Cardiology (HFA-ESC) brought a comprehensive overview and an algorithm for the diagnosis of HFpEF. ${ }^{4}$

\section{Four basic elements for the diagnosis of HFpEF are:}

1) Recognition of typical signs and symptoms (e.g. dyspnea, fatigue, reduced exercise tolerance, and signs of congestion) and comorbidities related to $\mathrm{HF}^{5}{ }^{5}$

2) Preserved left ventricular systolic function, i.e., ejection fraction (LVEF) $\geq 50 \%$;

3) Left atrium and left ventricle (LV) remodeling;

4) Direct or indirect evidence of high left ventricular filling pressure.

\section{Keywords}

Heart Failure/ophysiopathology; Stroke Volume; Diagnostic Imaging; Echocardiography/methods; Dyspmea; Fatigue; Vascular Stiffness; Comorbidity.

\footnotetext{
Mailing Address: Luiz Claudio Danzmann •

Rua Visconde do Herval, 472/903. Postal Code 90130-150,

Porto Alegre, RS - Brazil

E-mail: luiz.danzmann@ulbra.br

Manuscript received April 28, 2021, revised manuscript May 10, 2021, accepted June 01, 2021
}

\section{Diagnosis based on three steps}

In a recently published article, ${ }^{6}$ we propose a compilation of the Brazilian Society of Cardiology (SBC) Guidelines, Mayo Clinic, and HFA-ESC criteria adapted to the national health system. It recommends an approach in three degrees of complexity, adapting the use of resources from primary care (step 1) to the high complexity health centers (steps 2 and 3) (Figure 1).

\section{Step 1: Pre-test clinical approach.}

- Anamnesis: identification of signs and symptoms that offer the possibility of HF;

- Comorbidities: diagnosis of the clinical characteristics and major morbidities associated with risk of HFpEF, such as age $>60$ years, female sex, obesity, hypertension, diabetes, ischemic heart disease, and atrial fibrillation.

- Agonist or competing comorbidities of HF: agonists to decreased functional capacity, or are a differential diagnosis, such as anemia, chronic obstructive pulmonary disease, asthma, pulmonary fibrosis, peripheral arterial disease, sarcopenia, thyroid diseases, nephropathies, and electrolyte imbalance.

- Basic tests: blood cell count, creatinine, urea, glycemia, lipid profile, electrocardiogram (EKG), and chest X-ray.

- Natriuretic peptides (NPs): have a consolidated role in HF diagnosis. In patients with atrial fibrillation, serum values can rise 3 to 3.5 times, but in obese patients, this may significantly decrease. The following are accepted cutoff points: B-type natriuretic peptide (BNP) $\leq 35 \mathrm{pg} / \mathrm{mL}$ and/or $\mathrm{N}$-terminal-pro-BNP (NT-proBNP) $\leq 125 \mathrm{pg} / \mathrm{mL}$ make a diagnosis of HFpEF less likely. ${ }^{3}$

- Noninvasive cardiac tests: EKG, echocardiography (ECHO) to estimate LVEF and, in case of suspected myocardial ischemia, provocative tests as the treadmill test.

- Functional capacity tests: the 6-minute walk test, cardiopulmonary tests, and spirometry offer practical information on functional capacity. Ergospirometry-derived indices are the gold standards on functional capacity but are rarely available outside high complexity health units.

In this step, if the clinical, biomarkers and echocardiographic indices are unmistakably altered, HFpEF should be confirmed; however, a normal resting EKG and normal serum levels of NPs make the diagnosis of HFpEF less likely, although normal levels of NPs do not exclude HFpEF. 


\section{Brief Communication}

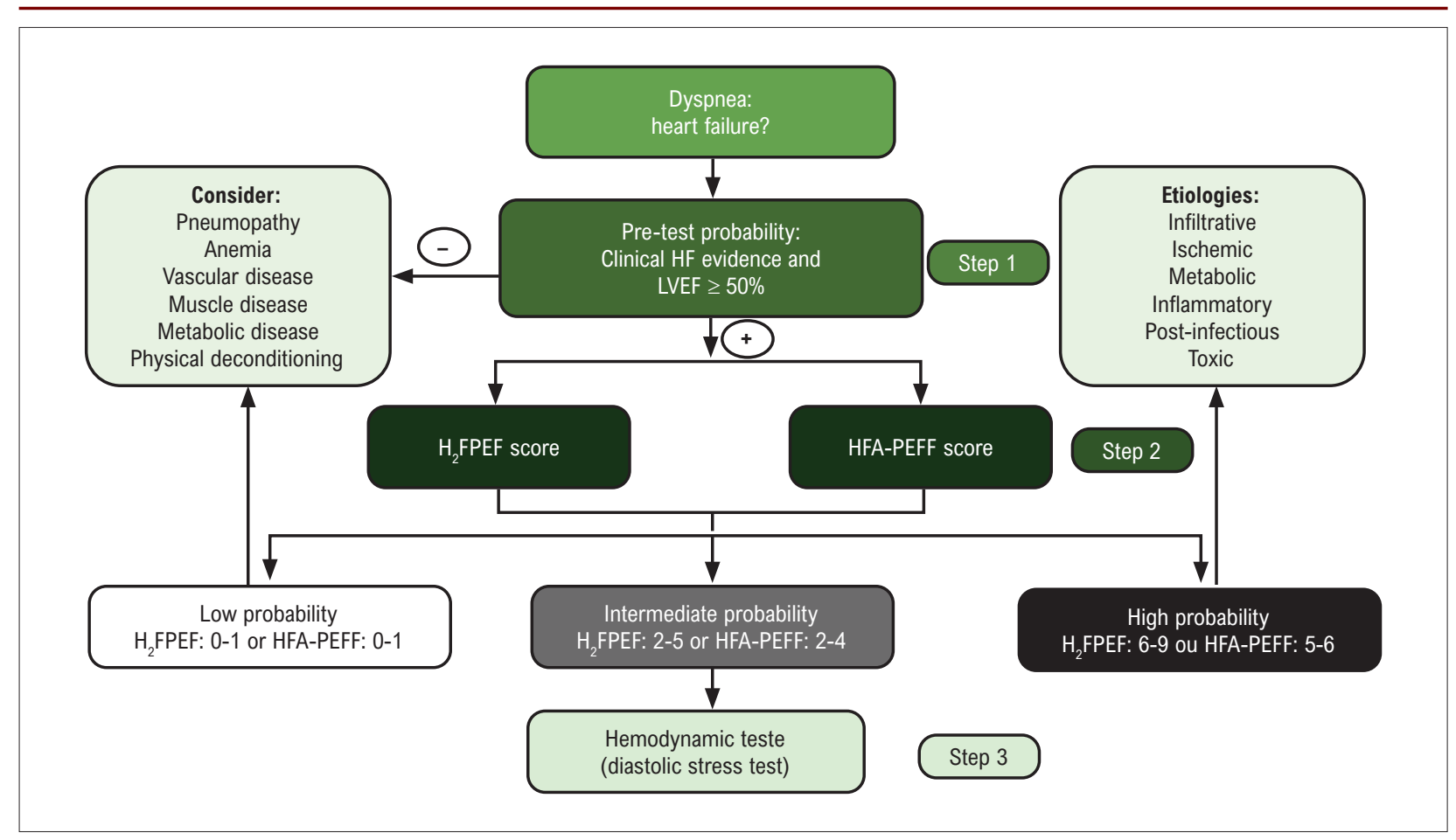

Figure 1 - Diagnostic algorithm for HFpEF. HF: heart failure; LVEF: left ventricular ejection fraction.

\section{Step 2 - Confirmatory scores}

If there is still doubt on the diagnosis of the syndrome, the next proposal is to confirm it with scoring. The $\mathrm{H}_{2} \mathrm{FPEF}$ and HFA-PEFF have recently been developed to establish the probable diagnosis of HFpEF. ${ }^{4,5}$ They were validated in retrospective cohorts and demonstrated a higher diagnostic accuracy. ${ }^{5,7}$ These scores are offered in parallel, depending on their availability. The $\mathrm{H}_{2}$ FPEF score was derived from clinical and echocardiographic variables that were independently associated with the invasive diagnosis of HFpEF in a population-based cohort. Each criterion generate a score that will estimate the probability of diagnosing the syndrome (Figure 2).

The other available score, HFA-PEFF, is composed of morphological and functional parameters, derived from a comprehensive $\mathrm{ECHO}$, along with serum levels of NPs. A model of major and minor criteria is used to score and estimate the diagnostic probability (Figure 3).

In this strategy, using any of two scores, HFpEF can be ruled out in patients with low scores ( 0 or 1 ) and confirmed with higher scores $\left(\mathrm{H}_{2}\right.$ FPEF $\geq 6$ or HFA-PEFF $\left.\geq 5\right)$. Conversely, in patients with intermediate scores $\left(\mathrm{H}_{2}\right.$ FPEF 2-5 or HFA-PEFF 2-4), an invasive or either a non-invasive hemodynamic exercise test is necessary (Figure 1).

\section{Step 3: Diastolic stress test or invasive investigation}

A diastolic stress test should be added to the preceding approach of HFpEF if measurements of diastolic function are inconclusive at rest, like when $\mathrm{H}_{2}$ FPEF score sums
2-5 points and HFA-PEFF score sums 2-4 points, respectively. Stress ECHO (SE) is capable of studying diastole, along with systolic function based on E/e' ratio, which estimates the LV filling pressure plus the tricuspid valve regurgitation velocity (TRV), thus allowing for the estimation of the pulmonary artery systolic pressure.

According to the HFA-PEFF consensus, ${ }^{4}$ an additional score is added to the one of step 2 ( 2 points if $\mathrm{E} / \mathrm{e}^{\prime}$ ratio $\geq 15$; 3 points if $\mathrm{E} / \mathrm{e}^{\prime}$ ratio $\geq 15$ and TRV $>3.4 \mathrm{~m} / \mathrm{s}$ ). If the final sum is $\geq 5$, diagnostic criteria for HFpEF are reached. Diastolic $\mathrm{SE}$ is positive for diagnosing if the average peak $\mathrm{E} / \mathrm{e}^{\prime}$ ratio is $\geq 15$, with or without a peak TRV $\geq 3.4 \mathrm{~m} / \mathrm{s}$.

If diastolic SE does not provide confirmation, an invasive measurement of pulmonary capillary wedge pressure at rest or during SE is indicated. Invasive strategy, although more expensive and less available, is still the gold standard diagnostic method.

\section{Etiological investigation}

Once the diagnosis is confirmed, focus should be directed to the systematic search for etiology, which can be divided into primary and secondary. ${ }^{6}$ The primary form combines common metabolic and hemodynamic characteristics, such as obesity, diabetes, and hypertension. The secondary form, which is less common, has specific etiologies such as ischemic, infiltrative, restrictive, inflammatory, infectious, toxic, or genetic, and should be actively sought. Mimics of HFpEF have diagnostic clues to aid early identification of phenocopies comprising constrictive pericarditis, primary valvular heart disease, or high-output syndrome, which should not be considered as 


\begin{tabular}{|c|c|c|c|}
\hline Score label & Clinical variable & Characteristics & Points \\
\hline \multirow[b]{2}{*}{$\mathrm{H}_{2}$} & Heavy & $\mathrm{IMC}>30 \mathrm{~kg} / \mathrm{m}^{2}$ & 2 \\
\hline & Hypertension & $\begin{array}{l}2 \text { or more } \\
\text { anti-hypertensive drugs }\end{array}$ & 1 \\
\hline $\mathbf{F}$ & Atrial fibrilation & Paroxistic or persistent & 3 \\
\hline $\mathbf{P}$ & Pulmonary hypertension & $\begin{array}{c}\text { PSAP }>35 \mathrm{mmHg} \\
\text { (measured on Doppler ECHO) }\end{array}$ & 1 \\
\hline E & Elderly & Age $>60$ years & 1 \\
\hline $\mathbf{F}$ & Filling pressures & $\begin{array}{c}\text { E/e' ratio }>9 \\
\text { (measured on Doppler ECHO) }\end{array}$ & 1 \\
\hline
\end{tabular}

Figure $2-H_{2} F P E F$ score. BMI: body mass index; PASP: pulmonary artery systolic pressure; ECHO: echocardiography; E/e': left ventricular filling pressure non-invasive index.

Ref. Reddy YNV, Carter RE, Obokata M, Redfield MM, Borlaug BA. A Simple, Evidence-Based Approach to Help Guide Diagnosis of Heart Failure With Preserved Ejection Fraction. Circulation. 2018;138(9):861-870.

\begin{tabular}{|c|c|c|c|}
\hline & Domain & Major criteria (2 points) & Minor criteria (1 points) \\
\hline $\begin{array}{l}\text { H } \\
\text { F } \\
\text { A }\end{array}$ & Functional & $\begin{array}{c}\mathrm{e}^{\prime} \text { septal }<7 \text { or } \\
\mathrm{e}^{\prime} \text { lateral }<10 \text { or } \\
\text { E/e }>15 \text { or } \\
\text { TRV }>2.8 \mathrm{~m} / \mathrm{s} \\
(\mathrm{PSAP}>35 \mathrm{mmHg})\end{array}$ & $\begin{array}{l}\text { E/e': } 9-14 \text { or } \\
\text { GLS }<16 \%\end{array}$ \\
\hline $\begin{array}{l}E \\
F \\
F\end{array}$ & Morphological & $\begin{array}{c}\mathrm{LAVI}>34 \mathrm{~mL} / \mathrm{m}^{2} \text { or } \\
\mathrm{LVMI}>149 / 122 \mathrm{~g} / \mathrm{m}^{2}(\mathrm{M} / \mathrm{W}) \text { and } \\
\text { RWT }>0.42\end{array}$ & $\begin{array}{l}\text { LAVI: } 29-34 \mathrm{~mL} / \mathrm{m}^{2} \text { or } \\
\text { LVMI }>115 / 95 \mathrm{~g} / \mathrm{m}^{2}(\mathrm{M} / \mathrm{W}) \text { or } \\
\text { RWT }>0.42 \text { or } \\
\text { Left ventricle wall tchickness } \\
\quad \geq 12 \mathrm{~mm}\end{array}$ \\
\hline $\begin{array}{l}\mathbf{0} \\
\mathbf{R}\end{array}$ & Biomarker (sinus rythm) & $\begin{array}{c}\text { BNP }>80 \mathrm{pg} / \mathrm{mL} \text { or } \\
\text { NT-proBNP }>220 \mathrm{pg} / \mathrm{mL}\end{array}$ & $\begin{array}{c}\text { BNP: } 35-80 \mathrm{pg} / \mathrm{mL} \text { or } \\
\text { NT-proBNP: } 125-220 \mathrm{pg} / \mathrm{mL}\end{array}$ \\
\hline $\mathrm{E}$ & Biomarker (atrial fibrillation) & $\begin{array}{c}\text { BNP }>240 \mathrm{pg} / \mathrm{mL} \text { or } \\
\text { NT-proBNP }>660 \mathrm{pg} / \mathrm{mL}\end{array}$ & $\begin{array}{l}\text { BNP: } 105-240 \mathrm{pg} / \mathrm{mL} \text { or } \\
\text { NT-proBNP: } 365-660 \mathrm{pg} / \mathrm{mL}\end{array}$ \\
\hline
\end{tabular}

Figure 3 - HFA-PEFF score. TRV: tricuspid valve regurgitation velocity; PASP: pulmonary artery systolic pressure; LAVI: left atrial volume; LVMI: left ventricular mass index; M: men / W: women; RWT: relative wall thickness; BNP: B-type natriuretic peptide; NT-proBNP: N-terminal pro-B-type natriuretic peptide; GLS: global longitudinal strain; e': early diatolic myocardial velocity.

Ref. Pieske B, Tschöpe C, de Boer RA, et al. How to diagnose heart failure with preserved ejection fraction: the HFA-PEFF diagnostic algorithm: a consensus recommendation from the Heart Failure Association (HFA) of the European Society of Cardiology (ESC). Eur J Heart Fail. 2020;22(3):391-412.

the HFpEF syndrome, since the latter can determine different clinical outcomes; therefore, a definitive diagnosis is necessary. The big challenge is to adapt the diagnostic strategy for each health system, without unfocusing on the best practice of evidence-based medicine.

\section{Author Contributions}

Conception and design of the research, Writing of the manuscript and Critical revision of the manuscript for intellectual content: Danzmann LC, Belyavskiy E, Jorge AJL, Mesquita ET, Torres MAR; Acquisition of data and Analysis and interpretation of the data: Danzmann LC, Jorge AJL, Mesquita ET; Statistical analysis and Obtaining financing: Danzmann LC.

\section{Ethics approval and consent to participate}

This article does not contain any studies with human participants or animals performed by any of the authors.

\section{Potential Conflict of Interest}

No potential conflict of interest relevant to this article was reported.

\section{Sources of Funding}

There were no external funding sources for this study.

\section{Study Association}

This study is not associated with any thesis or dissertation work. 


\section{Brief Communication}

\section{References}

1. Jorge AL, Rosa ML, Martins WA, Correia DM, Fernandes LC, Costa JA, et al. The Prevalence of Stages of Heart Failure in Primary Care: A PopulationBased Study. J Card Fail. 2016 Feb;22(2):153-7.

2. ComitêCoordenador da Diretriz de Insuficiência Cardíaca, Diretriz Brasileira de Insuficiência Cardíaca Crônica e Aguda. Arq Bras Cardiol. 2018Sep;111(3):436539. Portuguese. Erratum in: Arq Bras Cardiol. 2019 Jan;112(1):116.

3. Ponikowski P, Voors AA, Anker SD, Bueno H, Cleland JG, Coats AJ, et al. 2016 ESC Guidelines for the diagnosis and treatment of acute and chronic heart failure: The Task Force for the diagnosis and treatment of acute and chronic heart failure of the European Society of Cardiology (ESC). Developed with the special contribution of the Heart Failure Association (HFA) of the ESC. Eur J Heart Fail. 2016 Aug; 18(8):891-975.

4. Pieske B, Tschöpe C, de Boer RA, Fraser AG, Anker SD, Donal E, et al. How to diagnose heart failure with preserved ejection fraction: the
HFA-PEFF diagnostic algorithm: a consensus recommendation from the Heart Failure Association (HFA) of the European Society of Cardiology (ESC). Eur Heart J. 2019 Oct 21;40(40):3297-317.

5. Reddy YN, Carter RE, Obokata M, Redfield MM, Borlaug BA. A Simple, Evidence-Based Approach to Help Guide Diagnosis of Heart Failure With Preserved Ejection Fraction. Circulation. 2018; 138(9):861-70.

6. Silva MM, Rocha R, Brito FS, Jorge AJ, Issa VS, Danzmann LC. Emerging Topics in Heart Failure: Heart Failure With Preserved and Mid-Range Ejection Fraction. Arq Bras Cardiol. 2020 Nov;115(5):949-52.

7. Aizpurua AB, Wijk SS, Rocca HP, Henkens M, Heymans S, Nelson $L$, et al. Validation of the HFA-PEFF score for the diagnosis of heart failure with preserved ejection fraction. Eur J Heart Fail. 2020 Mar;22(3):413-21. 